Grand Valley State University

ScholarWorks@GVSU

1998

\title{
Investment Decisions by Individuals and Groups in 'Sunk Cost' Situations: The Potential Impact of Shared Representations
}

Christine M. Smith

Grand Valley State University, smithc@gvsu.edu

R. S. Tindale

Loyola University Chicago

Linda Steiner

Loyola University Chicago

Follow this and additional works at: https://scholarworks.gvsu.edu/psy_articles

Part of the Psychology Commons

\section{ScholarWorks Citation}

Smith, Christine M.; Tindale, R. S.; and Steiner, Linda, "Investment Decisions by Individuals and Groups in 'Sunk Cost' Situations: The Potential Impact of Shared Representations" (1998). Peer Reviewed Articles. 33.

https://scholarworks.gvsu.edu/psy_articles/33

This Article is brought to you for free and open access by the Psychology Department at ScholarWorks@GVSU. It has been accepted for inclusion in Peer Reviewed Articles by an authorized administrator of ScholarWorks@GVSU.

For more information, please contact scholarworks@gvsu.edu. 


\title{
Investment Decisions by
} Individuals and Groups in 'Sunk Cost' Situations: The Potential Impact of Shared Representations

\author{
Christine M. Smith \\ Department of Psychology, Grand Valley State University \\ R. Scott Tindale and Linda Steiner \\ Department of Psychology, Loyola University Chicago
}

Past research has shown that individuals prefer to continue investing resources into a failing endeavor once a considerable investment has been made, even when abandoning the project would be more rational economically. This phenomenon has been labeled the sunk cost effect (Arkes \& Blumer, 1985). Since investment decisions are often made by groups, we compared individual and group propensities for falling prey to the sunk cost effect. We also varied whether or not individuals and groups needed to justify their investment decision to a superior. Both individuals and groups showed the sunk cost effect. Group process analyses showed that error-prone majorities were more powerful than more rational minorities. In addition, group decisions seemed to be a function of two competing task representations - one favoring the sunk cost interpretation and the other favoring economic rationality.

KEYWORDS group decision making, shared representations, sunk cost

ONE of the more consistent findings that has emerged in the extensive group problem solving/decision making literature is that groups tend to be better at solving problems and making decisions than individuals working alone (Davis, 1969; Steiner, 1972). One of the first explanations for this phenomenon was that groups could engage in error-checking, thereby reducing the likelihood of the group collectively choosing an incorrect solution (Shaw, 1932). Although this explanation has received some empirical support, several combinatorial mathematical models of group performance (e.g., Davis, 1973; Lorge \& Solomon, 1955; Smoke \& Zajonc, 1962) have shown that the

\footnotetext{
Author's note

Address correspondence to Christine M. Smith, Department of Psychology, Grand Valley State University, Allendale, MI 49401, USA.

[email: SmithC@gvsu.edu]
} 
differences found between groups and individuals with respect to problem solving can be understood in the absence of the error-checking explanations.

Social Decision Scheme Theory (SDS; Davis, 1973 ) is one such model of group performance. Social decision schemes (SDSs) are rules that represent how groups combine each individual's preference within the group into a single collective decision. For example, a laboratory group working on a math problem may work under a 'truth-wins' SDS. This decision scheme implies that group members will collectively choose a correct solution to a problem if at least one of the members knows the correct answer. If the same group operates under a 'truth supported-wins' SDS, group members will collectively choose a correct solution if at least two of them agree upon the correct response. A 'majority-wins' SDS implies that the group will choose the alternative that the majority of the group members endorse. Davis (1973) has made several contributions to the small group literature with SDS theory. One of the most important contributions, however, has been its use in developing dimensions along which group tasks can be defined. Without a task classification system, little can be said about the relationship between group tasks and group performance. Davis and his colleagues have found systematic variations in the SDS under which groups operate as a result of task type (Davis, Laughlin, \& Komorita, 1976; Johnson, Davis, \& Kauma, 1972).

The intellective-judgmental task dimension classifies tasks with regard to whether or not a demonstrably correct solution to the problem exists (Laughlin \& Adamopoulos, 1980). Intellective tasks result in final products that can be evaluated objectively in terms of their correctness. In contrast, judgmental tasks are those for which no objectively or demonstrably correct solution exists. A 'truth-wins' SDS appears to be the best fitting model for most problems with extremely high demonstrability (e.g., the remote associates test), although in some instances it overpredicts group performance. Groups working on tasks with correct solutions that are lower in demonstrability typically oper- ate under a 'truth supported-wins' SDS. Groups working on tasks that fall closer to the judgmental end of the intellective-judgmental dimension operate under a 'strong majority-wins' SDS (e.g., jury decision making is the best exemplar and most researched task of this type). In summary, using SDS theory, it has been concluded that (a) groups working on tasks high in demonstrability can be expected to perform near the performance of their best member, and (b) when working on tasks with less compelling correct answers, groups will perform at or near the level of their second best member.

An apparent qualification to the general principle that groups tend to be better problem solvers than individuals working alone has been put forth and empirically supported by Tindale and his colleagues (e.g., Nagao, Tindale, Hinsz, \& Davis, 1985; Tindale, 1989; Tindale, Filkins, Thomas, \& Smith, 1993; Tindale, Sheffey, \& Filkins, 1990; Tindale, Smith, Thomas, Filkins, \& Sheffey, 1996). They have identified a set of problems on which group performance is inferior to that of individuals. Utilizing Laughlin's demonstrability dimension and the extensive work within the area of individual problem solving and cognitive heuristics (e.g., Kahneman, Slovic, \& Tversky, 1982), Tindale et al. (1996) have shown that group performance is inferior to individual performance when strong decision biases are present at the individual level, or when cognitive heuristics are used to solve the problem. To some extent increased group error rates can be explained in terms of the social decision scheme under which the group operates. That is, group error rates will exceed individual error rates if the group members are drawn from a biased population and the group operates under a majority-wins decision scheme (see Kerr, MacCoun, \& Kramer, 1996 for an interesting discussion of group error rates and SDSs). However, recent research has shown that under certain circumstances, decision biases at the individual level can create biases in the group decision process as well.

Tindale (1993) and Tindale et al. (1996) explain the group's inferior performance in terms of 'shared representations'. That is, the incorrect solution is often more compelling 
than the correct one because the group members share a task-relevant cognitive framework or strategy to solve the problem that favors the incorrect solution. The presence of a task-relevant shared representation results in an asymmetric group decision process where both majorities and minorities favoring the alternative consistent with the shared representation (even if it is incorrect) exert greater influence than factions favoring other alternatives (Tindale et al., 1990). That is, an incorrect minority may become very influential within a group if their explanation for endorsing a particular alternative is easily understood or particularly compelling (i.e., highly demonstrable although incorrect) to the other members. Tindale et al. (1996) noted such effects for a number of different decision tasks where different biases or errors are prevalent. For example, in two studies Tindale and his colleagues compared individual and group performance on a number of probability estimation problems involving conjunctions (Tindale et al., 1990, 1993). A conjunction error is one where individuals estimate the probability of a conjunctive event (e.g., 'Bill is an accountant who plays jazz for a hobby') to be higher than one or both of the elements that form the conjunction. Tversky and Kahneman (1983) explain the tendency for individuals to make the conjunction error in terms of the representativeness heuristic. That is, when one of the component elements is perceived to be highly likely and one is perceived to be unlikely, the conjunction is believed to be more representative of the object of judgment than is the unlikely event. Tindale et al. $(1990,1993)$ have shown that groups are more prone to make the conjunction error than are individuals. This is especially the case when the conjunction involves two likely events or one likely and one unlikely event. Additionally, simple majority influence processes do not seem to explain completely the exacerbation of the error at the group level. That is, in groups where a majority of members avoid the error prior to discussion, groups are more likely than not to make the error in their final collective decision (see Tindale et al., 1996, for a review of both studies mentioned).
One particular bias that has received only limited attention at the group level is the 'sunk cost effect' (Arkes \& Blumer, 1985). Past research has shown that individual decision makers prefer to continue investing resources into a failing endeavor once a considerable investment has been made, even when abandoning the project is more rational economically. This phenomenon has also been labeled 'entrapment' (Brockner \& Rubin, 1985) and the 'dead loss effect' (Kahneman \& Tversky, 1984). Several psychological explanations for escalation of commitment behavior have been discussed in the literature. One such explanation involves the notion of 'saving face' or 'impression management' (Staw, 1976). Based in part on the notion of cognitive dissonance (Festinger, 1957), this notion suggests that making an initial investment that later fails creates dissonance, which is aversive. The failure also makes the person appear to be a poor decision maker. Continued investment in a failing endeavor allows the decision maker to avoid appearing inconsistent with respect to her/his decisions and also provides an escape from admitting publicly that her/his initial decision to invest was a poor one (Caldwell \& O'Reilly, 1982). A similar explanation by Arkes and Blumer (1985) argues that people do not like to appear wasteful. Thus, to avoid the appearance of 'wasting' the initial investment, they continue to invest.

An alternative explanation for the 'sunk cost' error is derived from Kahneman and Tversky's (1979) 'prospect theory'. According to prospect theory, when problems are framed in terms of gains, individual decision makers tend to be risk averse. That is, they will prefer a solution that yields a relatively low payoff that is certain to one where the payoff is much higher but merely probable. The opposite is true of problems framed in terms of losses. Decision makers tend to prefer solutions that involve higher probable losses to those where the loss is relatively small but certain. Therefore, in sunk cost situations the decision maker is faced with a certain loss and may continue to invest in the hope that the additional resources will eliminate the loss entirely. 
Several situational and psychological factors have been shown to affect the tendency to make the sunk cost error, including investment size (Brockner, Rubin, \& Lang, 1981), the strength of personal association with the project (Staw \& Ross, 1989), the extent to which organizational change is possible (Staw \& Ross, 1989), and the amount of personal responsibility felt for the original investment decision (Arkes \& Blumer, 1985). Furthermore, researchers have shown that escalation of commitment occurs within the context of decision making groups (Kameda and Sugimori, 1993) and that a heightened group identity exacerbates the tendency to commit the 'sunk cost' error (Dietz-Uhler, 1996). Although Kameda and Sugimori (1993) and Dietz-Uhler (1996) have both shown that groups, like individuals, often escalate their commitment to failing endeavors, it was not the goal of either of these studies to compare individual escalation rates to those of groups. Two studies have made such a comparison.

In their investigation of an investment decision involving sunk cost, Bazerman, Giuliano, and Appelman (1984) found no differences between individuals and groups with respect to the amount of resources they allocated to a failing endeavor. That is, both groups and individual decision makers were equally likely to fall prey to the sunk cost error. Whyte (1993) investigated individuals' and groups' propensity to escalate their commitment to a failing endeavor by exploring investment decisions across six different scenarios. In contrast to the Bazerman et al. (1984) study, Whyte (1993) found that groups tended to exacerbate the bias found at the individual level in all instances. That is, groups were more likely to fall prey to the sunk cost effect than were individual decision makers. Perhaps most interesting, Whyte found asymmetries in the social influence patterns within the decision making groups in his study. Minorities in favor of escalating commitment were much more powerful than minorities arguing against escalation. Fifty percent of the groups with a minority faction favoring escalation ultimately escalated their commitment to the project whereas only 2 percent of the groups with minority factions favoring project abandonment ultimately abandoned the project.

These asymmetries found by Whyte (1993) are consistent with the Tindale et al. (1996) notion of shared representations. Whyte's group members may have shared a belief system that lent credence to the logic presented by group members favoring continued investment. In other words, although continuing to invest in a failing endeavor is not the economically rational alternative, it may be the most compelling and easily demonstrated alternative. The failure to find such effects by Bazerman et al. (1984) could be a function of the differences in the problems used. Tindale et al. (1996) have argued that some decision making problems may be associated with multiple task representations that tend to cancel each other out, leading groups to function under more typical, symmetric majority-type processes.

Consistent with past research, both Bazerman et al. (1984) and Whyte (1993) found that being held personally accountable for earlier investment decisions exacerbated the sunk cost effect for individuals and groups. Each study explored the effects of being held personally responsible by manipulating the individual who had made the earlier investment decision leading up to the sunk cost situation. High responsibility conditions were created by having the participants assume responsibility for the first investment decision, whereas low responsibility conditions were created by telling participants that someone other than they had made the earlier investment decision. Bazerman et al. (1984) explain the exacerbation of the sunk cost bias under conditions of high responsibility in terms of the need to justify to oneself the original investment decision. Arkes and Blumer (1985) hypothesized that both having one's own money at stake and/or being held personally accountable for the initial decision leading to the sunk cost decision should exacerbate the sunk cost effect.

\section{Overview}

In the present study we were interested in extending the literature on individual versus 
group error rates on problems involving 'sunk costs' by using a different sunk cost problem as well as by focusing upon the content of the rationales our decision makers used for their preferred choices. We also varied the personal responsibility of the decision maker by manipulating the role that the participants played (owner vs. manager). We were interested in whether or not the need to justify one's decision to a superior would reduce the rate of sunk cost errors. Consistent with our shared representations orientation, we were interested in determining whether or not there was a dominant way of framing the problem we used. If the dominant way of framing the problem involved emphasizing the sunk cost, groups should make more errors than individuals and the observed SDS matrices should show asymmetric deviations from majority processes in favor of the sunk cost decision. However, if multiple task representations are present in the group, groups may not exacerbate individuallevel error tendencies and majority-type processes should be represented in the observed SDS matrices.

\section{Method}

\section{Participants}

Altogether, 565 introductory psychology students participated as either individuals $(N=$ $165)$ or as members of five-person groups $(N=$ 400,80 groups). All participants received course credit for their participation and were randomly assigned to experimental conditions.

\section{Materials and procedures}

The experiment was introduced to participants as one that explored how individuals and groups made investment decisions. All participants were asked by the experimenter to imagine that they were either an owner (low need to justify to others) or a manager who must justify all decisions to the corporate board (high need to justify to others) of a printing company. They were also reminded of their role in the written instructions provided to them. All participants read the following scenario:
As the manager (owner) of a printing company, you must choose whether or not to modernize your operation by spending US $\$ 200,000$ on a new printing press or on a fleet of new delivery trucks. [Only for managers - You must also justify any purchasing decisions you make to the corporate board at their monthly board meetings.] You choose to buy the press, which works twice as fast as your old press at about the same cost as the old press (in the no sunk cost condition it is indicated in the scenario that the trucks, not the press, were purchased). One week after your purchase of the new press, one of your competitors goes bankrupt. To get some cash in a hurry, he offers to sell you his computerized printing press for $\$ 10,000$. This press works 50 percent faster than your new (old press in the no sunk cost condition) press at about one half the cost. You know you will not be able to sell your new (old) press to raise this money, since it was built specifically for your needs and cannot be modified. However, you do have $\$ 10,000$ in savings. The question is should you buy the computerized press from your bankrupt competitor? (Adapted from Arkes \& Blumer, 1985, p. 133).

The economically rational decision, regardless of which scenario is read, is to purchase the competitor's printing press. Arkes and Blumer (1985) found that participants were less likely to purchase the competitor's press when they had just spent the $\$ 200,000$ on a new printing press because of the perceived wastefulness of the initial printing press purchase. Thus, participants who bought the $\$ 200,000$ printing press commit the sunk cost error in that they forgo buying a more efficient cost effective printing press because they have recently invested a considerable amount of resources into the press they already own. Overall, the study conformed to a 2 (individual vs. group) $\times 2$ (initially bought press (sunk cost) vs. bought trucks (no sunk cost) ) $\times 2$ (owner vs. manager) factorial design.

All group participants, working individually, first decided whether to buy the competitor's press. They were also asked to indicate their level of confidence in their choice on a ninepoint scale ranging from 1 (not at all confident) to 9 (extremely confident). Finally, participants were asked to provide a brief written rationale for their choice. All individual response sheets were collected by the experimenter. Then participants in the group condition were asked to work on the problem 
collectively, to discuss with one another their individual preferences, and to reach consensus regarding the investment decision. They were provided a group response sheet on which they indicated their final decision. This sheet contained the complete text of the scenario as well as a reminder of the participants' status as a group of either owners or managers. There were no time limits placed upon the groups and all group discussions were timed. The researcher left the room during the group discussion phase of the experiment and returned when the participants indicated that they had reached a decision. After collecting the group's decision sheet, the experimenter asked that the participants respond to the problem once again as individuals. Each participant was given a response sheet with the scenario written on it. The experimenter indicated to the participants that she/he was not interested in whether or not they were consistent across their responses but only in their final individual decision regarding whether or not the printing press should be purchased. As before, confidence ratings and rationales were collected. The experimenter then debriefed the participants and thanked them for their participation.

Participants in the individual condition were given the same introduction as the groups and were given the same pretest sheet requiring that they make a decision regarding the purchase of the printing press. They were also asked to indicate their confidence in their decision and to write out a rationale for choosing the option they had. They then worked on an unrelated filler task. This task involved solving 10 syllogistic reasoning problems (these problems were being pilot tested for another research project and their content was unrelated to the printing press problem). After completing the syllogisms, individual participants were presented once again with the scenario and asked to make a decision regarding the purchase of the printing press. As was the case with the groups, individual participants were told that we were not interested in whether or not they were consistent across the pretest and posttest scenarios. Confidence data and written rationales were also collected. Individual participants were then debriefed and thanked for their participation.

\section{Results}

Second-set individual and group decisions were submitted to a 2 (individual vs. group) $\times 2$ (sunk cost vs. no sunk cost) $\times 2$ (justification managers vs. owners) log-linear cross-classification analysis. Table 1 shows the raw and relative frequencies of individuals and groups opting not to buy the competitor's printing press (i.e., making the sunk cost error) under both sunk cost and no sunk cost conditions. The model provided an adequate fit of the observed data $(p>.20)$ after all three main effects and all twoway interactions (individual-group by sunk cost, individual-group by justification, and sunk cost by justification) were entered $\left(\chi^{2}(1, N=\right.$ $243)=0.811, p=.368)$. Several effects were found to influence the fit of the model. First, there was a main effect for the sunk cost manipulation $\left(\chi^{2}(1, N=243)=45.38, p<.01\right)$. More groups and individuals decided against purchasing the competitor's printing press (i.e., made the sunk cost error) when they had just purchased a new printing press themselves $(53.2 \%)$ than when they had just purchased a fleet of delivery trucks (13.4\%). A main effect was found for group versus individual decision condition $\left(\chi^{2}(1, N=243)=4.62, p<.05\right)$. Fewer groups decided against buying the competitor's printing press $(25 \%)$, than did individuals $(38 \%)$. There was also a marginal main effect for whether or not the decision needed to be justified to others $\left(\chi^{2}(1, N=243)=3.03\right.$, $p<.10)$. Participants who role-played managers (i.e., those who needed to justify their decision to a superior) decided against buying the printing press less frequently $(28.6 \%)$ than did those who role-played owners $(38.7 \%)$. There was a significant justify by sunk cost condition interaction $\left(\chi^{2}(1, N=243)=5.27, p<.05\right)$. Participants who role-played owners in the sunk cost condition were much more likely to make the sunk cost error $(64.1 \%)$ than participants roleplaying managers in the sunk cost condition $(41.7 \%)$. There was almost no difference in the 
Table 1. Individual and group decisions for owners and managers in the sunk cost and no sunk cost conditions (relative frequencies are in parentheses)

\begin{tabular}{lrrrrr}
\hline & \multicolumn{2}{c}{ Sunk cost } & & \multicolumn{2}{c}{ No sunk cost } \\
\cline { 2 - 3 } \cline { 5 - 6 } & Individuals & Groups & & Individuals & Groups \\
\hline Owners & & & & \\
Correct & $12(.27)$ & $11(.55)$ & $33(.83)$ & $20(1.0)$ \\
Incorrect & $32(.73)$ & $9(.45)$ & $7(.17)$ & $0(0.0)$ \\
Managers & & & & \\
Correct & $24(.60)$ & $11(.55)$ & $32(.82)$ & $18(.90)$ \\
Incorrect & $16(.40)$ & $9(.45)$ & $7(.18)$ & $2(.10)$ \\
\hline
\end{tabular}

rate at which owners $(11.7 \%)$ and managers (15.3\%) decided against buying the press in the no sunk cost condition. ${ }^{1}$

Individual and average group-member confidence ratings were submitted to a 2 (individual vs. group) $\times 2$ (initially bought press vs. bought trucks) $\times 2$ (owner vs. manager) $\times 2$ (time - pretest and posttest) analysis of variance. There was a main effect for time (the repeated measure) $(F(1,552)=71.55, p<.001)$. Confidence ratings at time $2(M=7.52)$ exceeded those given at the pretest $(M=6.85)$. In addition, there was a statistically significant difference between group and individual confidence ratings $(F(1,552)=16.64, p<.001)$. Groups were more confident $(M=7.75)$ than individuals $(M=6.93)$. A two-way interaction indicated that group confidence increased more from pretest to posttest $(M=6.89$ and 7.75 , respectively) than did individual confidence $(M=6.77$ and 6.93, respectively) $(F(1,552)=34.06, p<.001)$. Finally, Figure 1 shows the three-way interaction between time, individual versus group, and sunk cost condition, $F(1,552)=7.613, p=.006)$. The locus of this three-way interaction is found in the twoway interaction between time and sunk cost condition in the group confidence data $(F(1,78)=9.012, p=.004)$. That is, confidence ratings are similar in the sunk cost and no sunk cost conditions at the pretest whereas confidence increases much more at the posttest in the no sunk cost condition. There is no two-way interaction between time and sunk cost condi- tion in the individual confidence data $(F(1,159)$ $=1.76, p=.186)$. For the individuals, confidence levels in the sunk cost and no sunk cost conditions are not significantly different at pretest or at posttest.

To assess generally the group decision processes and whether minorities favoring the sunk cost decision were more influential than minorities favoring the rational decision, we ran an SDS analysis (Davis, 1973) for the sunk cost and no sunk cost conditions separately. Table 2 shows the observed SDS matrices for the two conditions. Several models provided adequate fits to the data (i.e., could not be statistically rejected, $p<.20$ ), but as can be seen in the table, a majority model provided a very strong fit for both matrices (a majority model fit perfectly the no sunk cost condition). Additionally, although there was some evidence of minority influence in the sunk cost condition, the asymmetries predicted by the shared representation interpretation were not found. Majorities were equally powerful regardless of which alternative they favored.

To explore further the processes underlying the group decision results, we looked at the relationships between group member rationales for their decisions and their group

Table 2. Observed SDS matrices for sunk cost and no sunk cost conditions

\begin{tabular}{lccccc}
\hline \multicolumn{2}{c}{ Individuals } & & \multicolumn{2}{c}{ Groups } \\
\cline { 6 - 6 } Correct & Incorrect & $N$ & Correct & Incorrect \\
\cline { 5 - 6 } Sunk cost condition & & & & \\
5 & 0 & 3 & 1.00 & .00 \\
4 & 1 & 9 & 1.00 & .00 \\
3 & 2 & 8 & .75 & .25 \\
2 & 3 & 9 & .33 & .67 \\
1 & 4 & 7 & .14 & .86 \\
0 & 5 & 4 & .00 & 1.00 \\
& & & & \\
No sunk cost condition & & & .00 \\
5 & 0 & 18 & 1.00 & .00 \\
4 & 1 & 16 & 1.00 & .00 \\
3 & 2 & 4 & 1.00 & 1.00 \\
2 & 3 & 1 & .00 & - \\
1 & 4 & 1 & .00 & 1.00 \\
0 & 5 & 0 & - &
\end{tabular}


(a)

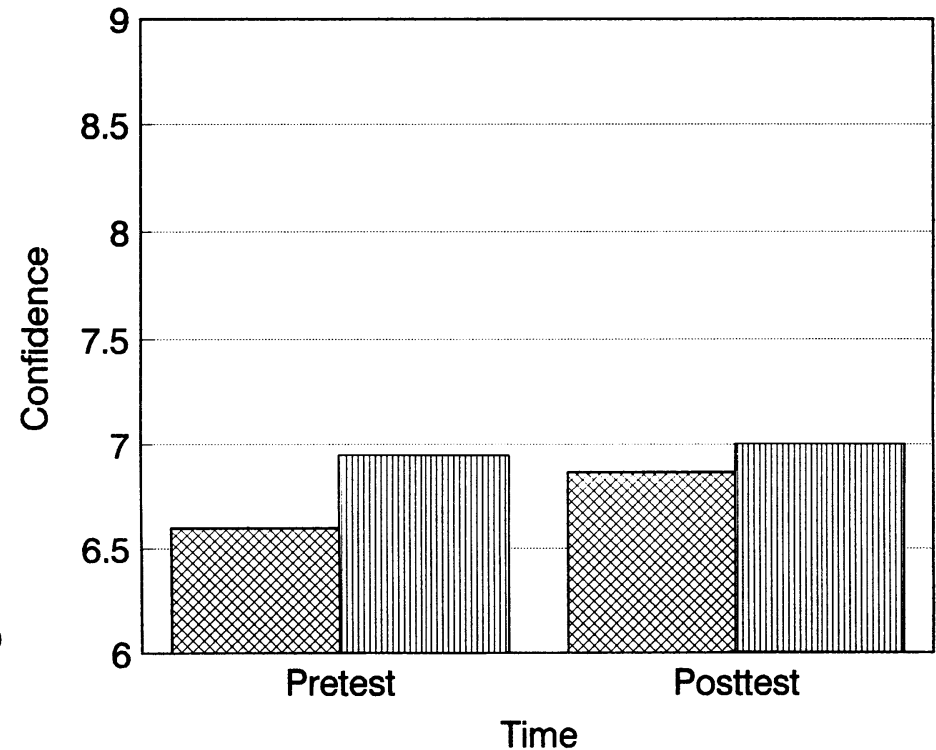

\section{Sunk Cost} 血No Sunk Cost

Time

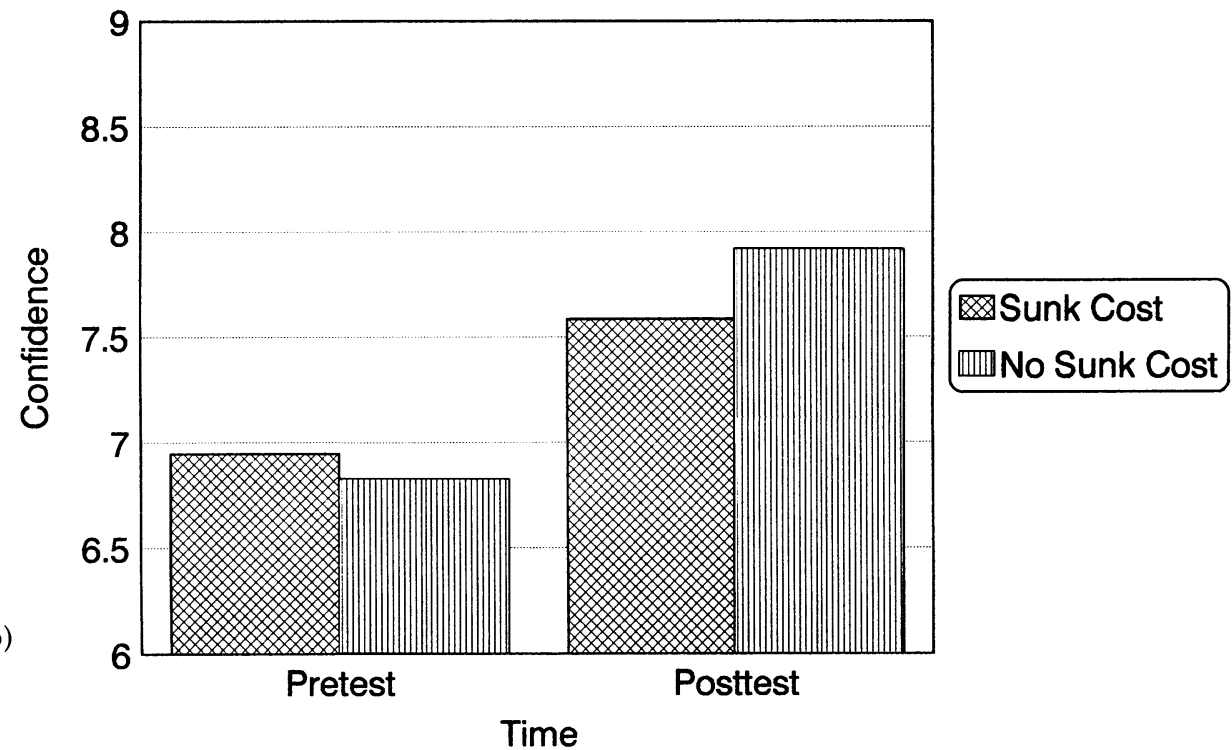

Figure 1. Pre- and post-confidence judgments by individuals (a) and groups (b) in the sunk cost and no sunk cost conditions.

decisions. First, each individual's pre- and postdiscussion written rationale were content analyzed by two independent coders blind to the hypotheses of the study (four different coders were used overall). We empirically developed four categories into which the rationales could be placed: (1) sunk cost; (2) should not deplete savings; (3) new press might not work 
out; and (4) new press will be more efficient (about $75 \%$ of all responses fit into one of these four categories). Rationales were categorized as 'sunk cost' if they contained statements implying that the press should not be purchased because the company had just invested $\$ 200,000$ in a press perfectly suited to its needs. Rationales were categorized as 'should not deplete savings' if the participant suggested it would be a bad idea to spend all of the company's savings on a press, or that the money should be saved for an emergency situation. Rationales were categorized as 'new press might not work out' if respondents believed that in buying the press the company may go bankrupt, or that the new press might not meet their needs as well as their current press. Finally, any rationale suggesting that the computerized press would be superior to the custom-made press was categorized as 'new press will be more efficient'. The developed categories were not treated as though they were mutually exclusive. That is, rationales could contain elements of several different categories and were coded as such. The inter-observer reliability (percent agreement) averaged across all coders for the entire data set (both prediscussion and postdiscussion rationales) was 72 percent (Cohen's kappas for each pair of coders ranged from .56 to .72 , all values significant at $p<.001$ ) . Discrepancies in the coders' original judgments were discussed by them until consensus was reached regarding the appropriate categorization for each rationale.

Figure 2 shows the percentages of participants who mentioned each of the four rationale categories at pretest. As shown in the figure, the 'more efficient' rationale was the dominant reason given in the overall sample. Additionally, even though the 'sunk cost' rationale was quite prevalent in the sunk cost condition, more participants mentioned the efficiency of the new press than mentioned 'sunk cost'. Thus, it appears that the 'sunk cost' rationale was shared by fewer than 50 percent of the group members, even in the sunk cost condition.

Although we were unable to record the group discussions, it seems reasonable to argue that the rationales written by group members prior to group discussion were highly likely to be mentioned during the group deliberations. ${ }^{2}$

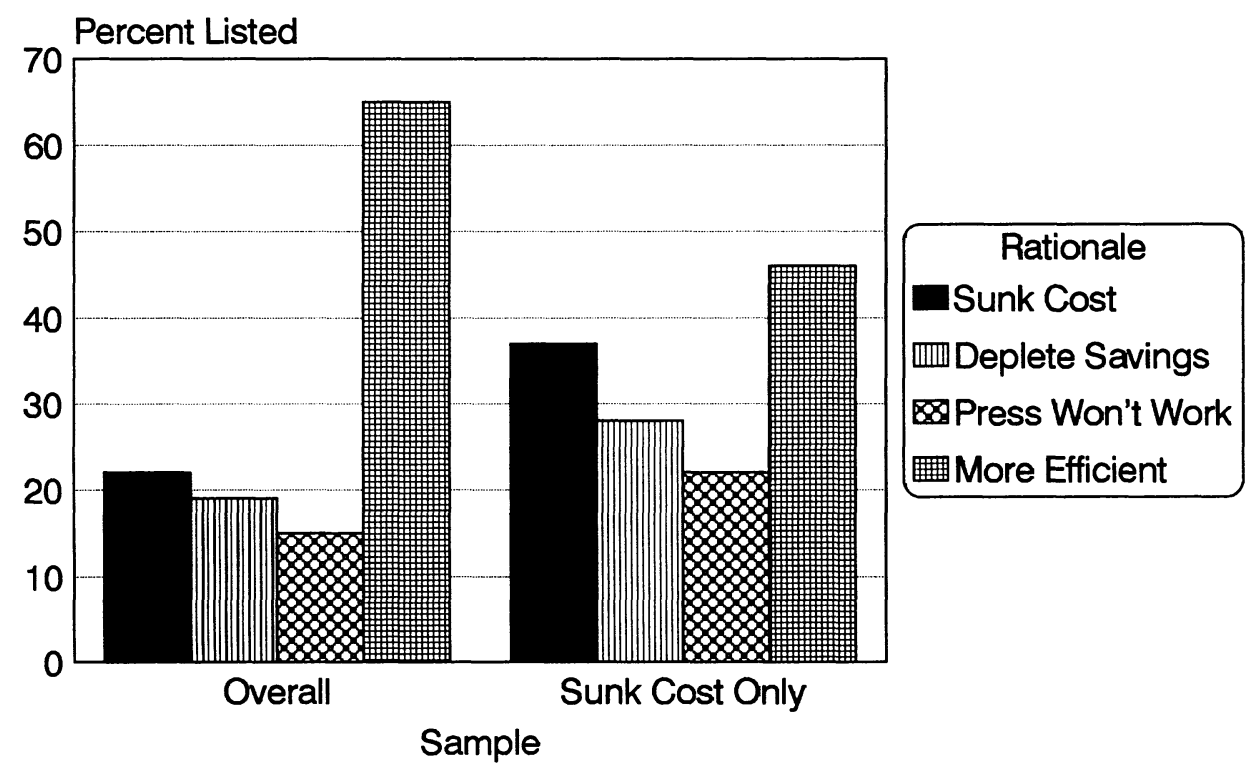

Figure 2. Percentage of participants listing each rationale: overall and only in the sunk cost condition. 
Thus, we summed the number of members in each group who mentioned statements consistent with each of the four categories in their rationales in the sunk cost condition. We did so in order to assess the relationship between the number of people mentioning the rationale and group decisions. We found significant associations between group decisions and the number of members mentioning the sunk cost rationale $\left(\chi^{2}(5, N=40)=20.50, p<.001\right)$, and the number of members mentioning the efficiency of the new press rationale $\left(\chi^{2}(5, N=\right.$ $40)=21.74, p<.001) .^{3}$ The data for these analyses are reported in Table 3 . As can be seen in the top portion of the table, the number of group members mentioning the sunk cost rationale was strongly related to the groups' likelihood of making the sunk cost error. In fact, even when only two members included the sunk cost argument in their rationales, the groups were more likely than not to make the error. However, the lower portion of Table 3 shows a similar but opposite pattern for the number of members listing the 'efficiency' argument in their rationales. As more members included the efficiency argument in their rationales, their groups became less likely to make the sunk cost error.

The above results tend to indicate that there were at least two fairly strong but competing ways to represent the problem we used in the sunk cost condition. The analyses presented below were oriented toward further exploring this possibility. First, if there were two competing representations in the sunk cost condition, it should have taken the groups longer to reach consensus in the sunk cost as compared to the no sunk cost condition - where one of the representations would not be present. The analysis of group decision times showed that groups in the sunk cost condition took almost twice as long to reach consensus ( $M=3.75$ minutes) when compared to groups in the no sunk cost condition $(M=2.01$ minutes $)(F(1,70)=4.91$, $p=.03)$. Next, we looked at the degree to which participants' rationales could be used to predict their individual choices. These data are presented in Table 4. As indicated, both the sunk cost rationale and the efficiency rationale
Table 3. Number of members listing sunk cost or efficiency rationales and final group decisions

\begin{tabular}{lccc}
\hline & \multicolumn{3}{c}{$\begin{array}{c}\text { Proportion of groups } \\
\text { deciding }\end{array}$} \\
\cline { 2 - 4 } \multicolumn{1}{c}{$N$} & Buy & Don't buy \\
\hline \multicolumn{2}{c}{ Members listing sunk cost } & \\
0 & 5 & 1.000 & .000 \\
1 & 14 & .857 & .143 \\
2 & 9 & .444 & .556 \\
3 & 9 & .111 & .889 \\
4 & 1 & .000 & 1.000 \\
5 & 2 & .000 & 1.000 \\
& & & \\
Members listing efficiency & & 1.000 \\
0 & 4 & .000 & .875 \\
1 & 8 & .125 & .556 \\
2 & 9 & .444 & .286 \\
3 & 7 & .714 & .000 \\
4 & 9 & 1.000 & .000 \\
5 & 3 & 1.000 & \\
\hline
\end{tabular}

were strongly related to the choices made, but the relationship between the efficiency rationale is significantly stronger $(z=14.86$, $p<.001){ }^{4}$

We also conducted a multiple regression analysis regressing group decisions onto the number of group members listing the sunk cost rationale and the number of members listing the efficiency rationale. The results are reported in Table 5 . As can be seen in the table, these two predictors accounted for over 50 percent of the variance and both were strongly correlated with group decisions. However, when both variables were entered into the regression equation, only the number of members listing the efficiency rationale received a significant

Table 4. Relations between individual pre-group choice and the sunk cost and efficiency rationales

\begin{tabular}{lcr}
\hline & Listed & Not listed \\
\hline Sunk cost rationale $(\phi=.717)$ & \\
Correct & 2 & 372 \\
Error & 120 & 71 \\
& & \\
Efficiency rationale $(\phi=-.946)$ & 11 \\
Correct & 363 & 188 \\
Error & 3 & \\
\hline
\end{tabular}


Table 5. Regression results predicting group decisions with number of members listing the sunk cost and the efficiency rationales in the sunk cost condition

\begin{tabular}{|c|c|c|c|c|}
\hline \multicolumn{5}{|c|}{$\begin{array}{l}R=.737 \\
R^{2}(\text { adj })=.519 \\
F(2,37)=22.03, p<.001\end{array}$} \\
\hline Predictor & $r$ & $\beta$ & $t$ & $p$ \\
\hline Sunk cost & .683 & .258 & 1.28 & .210 \\
\hline Efficiency & -.724 & -.616 & 2.51 & .017 \\
\hline
\end{tabular}

regression weight. This is not surprising because the two variables were negatively correlated $(r(38)=-.836, p<.001)$. However, it does show that the efficiency rationale was somewhat more powerful for this particular problem in our sample.

A second set of analyses was carried out using a combined index of the number of members listing the sunk cost rationale and the number of members listing the efficiency rationale. The index was defined as the absolute value of the difference between the number of members listing each rationale. Numbers at or near zero represent groups where both rationales were equally represented in the group and larger numbers (largest possible value $=5$ ) indicate that one or the other rationale was shared by a larger number of group members. Thus, the index is an imperfect measure of the degree to which multiple competing representations existed in the groups. The analysis utilizing this index focussed upon the groups in the sunk cost condition. Consistent with a competing representation explanation, the index was correlated negatively (though only marginally so) with group decision times $(r(38)=-.23, p=$ $.079)$. Groups where both rationales were represented in the group took longer to reach decisions. However, the index showed virtually no association with group confidence judgments $(r(38)=.04, p=.81)$, which is inconsistent with the competing representation idea. Interestingly, this lack of association between the index and confidence becomes clearer when confidence is correlated with each component of the index separately. The number of members listing the sunk cost rationale showed a significant positive correlation with group confidence $(r(38)=.365, p=.010)$. However, the number of members listing the efficiency rationale showed a non-significant negative correlation with confidence $(r(38)=-.197, p=$ .112). This is also consistent with the relation between group confidence and group decisions in the sunk cost condition; groups that made the sunk cost error were more confident than groups that did not make the error $(r(38)=$ $.269, p=.046)$. Thus, even though the efficiency rationale led groups away from making the sunk cost error, the sunk cost rationale (and the subsequent error) inspired more confidence.

\section{Discussion}

Consistent with previous findings (Bazerman et al., 1984; Whyte, 1993), we found that groups, as well as individuals, fall prey to the sunk cost error. Both individuals and groups were much less likely to buy the new printing press (i.e., make the less economically rational choice) when they were told they had spent $\$ 200,000$ on a new press as compared to when they spent the money on a new fleet of trucks. Our results concerning the owner-manager distinction are also consistent with previous research (e.g., Staw, 1976; although see Note 1). Arkes and Blumer (1985) argued that when one's own money/resources are at stake (as was the case for the owners), the likelihood of making the sunk cost error increases. In addition, the managers may have felt less responsible for their initial financial decision (buying the press or the trucks), as well as their second decision (buying vs. not buying the competitor's press) because they perceived the corporate board as having final approval (even though this was not explicitly stated in the scenario).

The shared representation idea presented earlier (Tindale et al., 1996) led us to predict that groups in the sunk cost condition would perform worse than individuals. Our results were inconsistent with our predictions, and with the findings of previous research (Bazerman et al., 1984; Whyte, 1993), in that groups 
performed somewhat better than individuals in that condition (but see Note 1). In addition, the shared representation predictions were not confirmed with the SDS analyses. The asymmetric pattern of influence favoring the sunk cost error response was not found. Majorities were quite influential regardless of which alternative they favored. However, the shared representation predictions were based on the assumption that a task representation favoring the error response would be strongly shared amongst the group members in the sunk cost condition. Our results seem to indicate that this was not the case. Even in the sunk cost condition, only 37 percent of the participants listed a sunk cost rationale to support their decision. Thus, the degree to which the sunk cost representation was shared was less than what we expected.

In addition, evidence for a second task representation that was somewhat more powerful than the sunk cost representation was found. The rationale that the new press would be more efficient was both more prevalent among participants in the sunk cost condition (and even more so in the no sunk cost condition) and was more strongly related to both the individual and group decisions. Thus, it appears that two partially shared and relatively powerful task representations existed for this task. Furthermore, the two representations were competing. That is, the sunk cost rationale led decision makers to make the error and the efficiency rationale led them to a correct decision. Under such circumstances, we would expect groups neither to exacerbate individual error tendencies nor to show asymmetries in the social decision schemes (Tindale et al., 1996). The results concerning the group decision times are also consistent with this reasoning. Groups took longer to make decisions in the sunk cost condition where competing representations were present, and within that condition, took longer to make decisions when both representations were equally represented among the group members.

The results concerning participants' confidence judgments potentially point out some interesting aspects of the cognitive processes associated with using the different representations discussed above. First, post-group confidence was higher for the group members in the no sunk cost condition as compared to group members in the sunk cost condition. Given that there was only one dominant representation in that condition, group members would be expected to show high degrees of confidence after their discussions. It should be noted that this could also be a function of the greater degree of initial consensus found for groups in the no sunk cost condition (see Table 2). However, within the sunk cost condition, we found a positive correlation between the number of members using the sunk cost rationale and the average post-group member confidence. The opposite results (a negative correlation) was found for the number of members using the efficiency rationale and confidence. This was also represented in the relationship between the decisions that groups made and their post-group member confidence. Groups that made the sunk cost error were more confident than groups that did not make the error. In addition to implying that group sunk cost errors may be particularly immune to change because of heightened member confidence, these results are also consistent with a number of the theoretical explanations for why people make sunk cost errors in the first place.

Most of the explanations for the sunk cost effect stem from some type of cognitive avoidance. For example, cognitive dissonance explanations involve decision makers avoiding or reducing the dissonance associated with the initial decision and the current negative outcomes. Arkes and Blumer (1985) argue that sunk cost errors help decision makers avoid feeling wasteful. In addition, prospect theory argues that decision makers make sunk cost errors to avoid the negative feelings associated with certain losses. All three explanations imply that decision makers should 'feel' better after following the sunk cost logic. On the other hand, decision makers who make the more rational decision should still feel dissonance, wasteful, or the negative affect associated with a loss that is certain. It is possible that the reduction of the negative feelings associated with 
making the sunk cost errors allows decision makers to feel more confident about their course of action. On the other hand, the negative feelings associated with making the sunk cost error remain when the rational choice is made, which may lead to lower confidence in the chosen course of action. Although we have no direct evidence to support this interpretation, future research could address this interpretation by directly assessing the feelings associated with choices made in sunk cost situations.

In summary, the current study demonstrates that groups can fall prey to the same types of errors as those made by individuals. In addition, the overall pattern of results seems to imply that focussing on the degree to which group members share particular decision rationales or task representations may aid in our understanding of when and if groups will be better or worse decision makers than individuals. Our results also indicate that a particular individual-level decision bias may not have the same implications for individual-group comparisons across different task types and situations. More emphasis is needed on the interaction between cognitive and social processes as instantiated in different task domains in order for us to understand more fully how individual-level biases will be reflected in group decision processes and outcomes.

\section{Notes}

1. The analyses reported here compared responses by participants in the individual condition to group responses. However, comparable analyses using group members' responses prior to grouping only showed a significant effect for the sunk cost manipulation. These analyses violate the independence assumption underlying the log linear approach, but they seem to indicate that individual responses were somewhat different than group member responses prior to grouping (particularly in the owner-sunk cost condition). Thus, the individual-group differences, and those involving the owner-manager distinction should be interpreted cautiously.

2. Although we have no way to empirically support this assumption in the present study, previous research has shown that over 60 percent of arguments mentioned in group member thought lists were represented in group discussions (Smith, Tindale, \& Dugoni, 1996). In addition, Tindale, Sheffey, and Scott (1993) found substantial relations between member decision rationales and both member and group decisions.

3. Although the number of people listing the other two rationales for not buying the press was also related to the group's propensity to make the error, the relationship stemmed mainly from the fact that often people listed more than one rationale. After controlling for the number of people listing the sunk cost rationale, the number of members listing the other two rationales no longer predicted group decisions.

4. The $z$ test reported here is based on the absolute values of the two correlations.

\section{References}

Arkes, H. R., \& Blumer, C. (1985). The psychology of sunk cost. Organizational Behavior and Human Decision Processes, 35, 124-140.

Bazerman, M. H., Giuliano, T., \& Appelman, A. (1984). Escalation of commitment in individual and group decision making. Organizational Behavior and Human Performance, 33, 141-152.

Brockner, J., \& Rubin, J. (1985). Entrapment in escalating conflict: A social psychological analysis. New York: Springer-Verlag.

Brockner, J., Rubin, J. Z., \& Lang, E. (1981). Facesaving and entrapment. Journal of Experimental Social Psychology, 17, 68-79.

Caldwell, D. F., \& O'Reilly, C. A. (1982). Responses to failures: The effects of choices and responsibility on impression management. Academy of Management Journal, 25, 121-136.

Davis, J. H. (1969). Group performance. Reading, MA: Addison-Wesley.

Davis, J. H. (1973). Group decision and social interaction: A theory of social decision schemes. Psychological Review, 80, 97-125.

Davis, J. H., Laughlin, P.R., \& Komorita, S. S. (1976). The social psychology of small groups: Cooperative and mixed-motive interaction. Annual Review of Psychology, 27, 501-541.

Dietz-Uhler, B. (1996). The escalation of commitment in political decision-making groups: A social identity approach. European Journal of Social Psychology, 26, 611-629.

Festinger, L. (1957). A theory of cognitive dissonance. Evanston, IL: Row, Peterson.

Johnson, C. D., Davis, J. H., \& Kauma, C. E. (1972). Individual-group risk distributions on choice dilemmas 
problems: A parametric study. Paper presented at the meeting of the Eastern Psychological Association, Boston, MA.

Kahneman, D., Slovic, P., \& Tversky, A. (1982). Judgment under uncertainty: Heuristics and biases. Cambridge, MA: Cambridge University Press.

Kahneman, D., \& Tversky, A. (1979). Prospect theory: An analysis of decisions under risk. Econometrica, 47, 263-291.

Kahneman, D., \& Tversky, A. (1984). Choices, values, and frames. American Psychologist, 39, 341-350.

Kameda, T., \& Sugimori, S. (1993). Psychological entrapment in group decision making: An assigned decision rule and groupthink phenomenon. Journal of Personality and Social Psychology, 65, 282-292.

Kerr, N.L., MacCoun, R. J., \& Kramer, G. P. (1996). 'When are $\mathrm{N}$ heads better (or worse) than one?': Biased judgment in individuals versus groups. In J. Davis \& E. Witte (Eds.), Understanding group behavior: Consensual action by small groups (Vol. 1). Hillsdale, NJ: Erlbaum.

Laughlin, P. R. , \& Adamopoulos, J. (1980). Social combination processes and individual learning for six-person cooperative groups on an intellective task. Journal of Personality and Social Psychology, 38, 941-947.

Lorge, I., \& Solomon, H. (1955). Two models of group behavior in the solution of Eureka-type problems. Psychometrika, 20, 139-148.

Nagao, D. H., Tindale, R. S., Hinsz, V. B., \& Davis, J. H. (1985). Individual and group biases in information processing. In R. S. Tindale \& D. H. Nagao (Co-Chairs), Cognitive factors in small group processes. Symposium conducted at the American Psychological Association Annual Convention, Los Angeles, CA.

Shaw, M. E. (1932). Comparison of individuals and small groups in the rational solution of complex problems. American Journal of Psychology, 44, 491-504.

Smith, C. M., Tindale, R. S., \& Dugoni, B. L. (1996). Minority and majority influence in freely interacting groups: Qualitative vs. quantitative differences. British Journal of Social Psychology: Special Issue on Minority Influence, 35, 137-149.

Smoke, W. H., \& Zajonc, R. B. (1962). On the reliability of group judgments and decisions. In J. H. Criswell, H. Solomon, \& P. Suppes (Eds.), Mathematical methods in small group process. Stanford, CA: Stanford University Press.

Staw, B. M. (1976). Knee deep in the big muddy: A study of escalating commitment to a chosen course of action. Organizational Behavior and Human Performance, 16, 27-44.

Staw, B. M., \& Ross, J. (1989). Understanding behavior in escalation situations. Science, 246, 216-220.

Steiner, I. (1972). Group process and productivity. New York: Academic Press.

Tindale, R. S. (1989). Group vs. individual information processing: The effects of outcome feedback on decision making. Organizational Behavior and Human Decision Processes, 44, 454-473.

Tindale, R. S. (1993). Decision errors made by individuals and groups. In N. J. Castellan, Jr. (Ed.), Individual and group decision making: Current issues (pp. 109-124). Hillsdale, NJ: Erlbaum.

Tindale, R. S., Filkins, J., Thomas, L. S., \& Smith, C. M. (1993). An attempt to reduce conjunction errors in decision making groups. Poster presented at the Society for Judgment and Decision Making Annual Meeting, Washington, DC.

Tindale, R. S., Sheffey, S., \& Filkins, J. (1990). Conjunction errors by individuals and groups. Paper presented at the Society for Judgment and Decision Making Annual Meeting, New Orleans, LA.

Tindale, R. S., Sheffey, S., \& Scott, L. A. (1993). Framing and group decision making: Do cognitive changes parallel preference changes? Organizational Behavior and Human Decision Processes, 55, 470-485.

Tindale, R. S., Smith, C. M., Thomas, L. S., Filkins, J., \& Sheffey, S. (1996). Shared representations and symmetric social influence processes in small groups. In J. Davis \& E. Witte (Eds.), Understanding group behavior: Consensual action by small groups (Vol. 1). Hillsdale, NJ: Erlbaum.

Tversky, A., \& Kahneman, D. (1983). Extensional vs. intuitive reasoning: The conjunction fallacy in probability judgments. Psychological Review, 90, 293-315.

Whyte, G. (1993). Escalating commitment in individual and group decision making: A prospect theory approach. Organizational Behavior and Human Decision Processes, 54, 430-455.

\section{Acknowledgments}

We would like to thank Dominic Abrams and three anonymous reviewers for their helpful comments on an earlier draft of this paper. We are grateful to Lyn VanSwol for assisting with the data collection 
and Sharon Massel, Shamar Strokosch, Bahar Azari, and Arthur Oberg for the time they devoted to content analyzing the written rationales.

Portions of these results were presented at the 1994 meetings of The Society for Judgment and Decision Making and at the 1998 meetings of the Nags Head International Conference on Groups, Networks, and Organizations.

Received 14 April 1998; revised version accepted 22 June 1998.

\section{Biographical notes}

CHRISTINe m. Smith is an Assistant Professor of Psychology at Grand Valley State University. Her research focuses upon minority influence in freely interacting discussion groups and individual versus group decision making. She currently serves as a consulting editor for Group Processes EO Intergroup Relations.

R. SCOTT TINDALE is a Professor and Director of the Applied Social Psychology Graduate Program at Loyola University Chicago. His research interests involve individual and group decision making and performance. He is currently an associate editor of Group Processes Ev Intergroup Relations and Personality and Social Psychology Bulletin, and is co-editor (with the Loyola Social Psychology Faculty) of the SPSSI series Social Psychological Application to Social Issues, serving as lead editor on the most recent volume (4) Theory and Research on Small Groups (1998). LINDA STEINER is a graduate student (ABD) in the Applied Social Psychology Program at Loyola University Chicago. Her research interests focus on race relations, stereotyping and prejudice, particularly in educational settings. She served as a consulting editor for the SPSSI series Social Psychological Applications to Social Issues. 